\title{
Students at the Center: Insights and Implications of Authentic, 5E Instruction in High School English Language Arts
}

\author{
Gage Jeter ${ }^{1 *}$, Jane Baber ${ }^{2}$, Benjamin Heddy ${ }^{2}$, Scott Wilson ${ }^{2}$, Leslie Williams ${ }^{2}$, \\ Linda Atkinson ${ }^{2}$, Sharon Dean ${ }^{2}$ and Gregg Gam ${ }^{2}$ \\ ${ }^{1}$ School of Teaching and Learning, University of Florida, Gainesville, FL, United States, ${ }^{2}$ K20 Center for Educational and \\ Community Renewal and the Department of Educational Psychology, University of Oklahoma, Norman, OK, United States
}

\section{OPEN ACCESS}

Edited by:

Heidi L. Hallman,

University of Kansas, United States

Reviewed by:

Jodi Nickel,

Mount Royal University, Canada

Anna Stetsenko,

City University of New York,

United States

*Correspondence:

Gage Jeter

gjeter@coe.ufl.edu

Specialty section:

This article was submitted to

Teacher Education,

a section of the journal

Frontiers in Education

Received: 04 June 2019

Accepted: 12 August 2019

Published: 06 September 2019

Citation:

Jeter G, Baber J, Heddy B, Wilson S,

Williams L, Atkinson L, Dean S and Gam G (2019) Students at the Center: Insights and Implications of Authentic, 5E Instruction in High School English

Language Arts. Front. Educ. 4:91

doi: 10.3389/feduc.2019.00091
This paper explores the 5E model of lesson design (engage, explore, explain, extend, evaluate) in English Language Arts (ELA) classrooms in consideration of an authentic teaching and learning framework. This quasi-experimental pre and post-intervention study centers on student motivation and academic emotions regarding direct instruction in comparison to an authentic, 5E lesson. When comparing pre and post conditions across two types of instructional methods (direct instruction and authentic, 5E lessons), findings suggest students are less interested and more bored when participating in direct instruction experiences. Moreover, academic pressure increased in the authentic group while classroom mastery decreased.

Keywords: authenticity, motivation, engagement, lesson design, English language arts

\section{INTRODUCTION}

From the hallway bustling with chatter enters a student brimming with excitement:

"Why did second hour get to do all that cool stuff and we just took notes? Are we going to get to do that essay lesson too?" While it is a pleasure for teachers to witness their students showing enthusiasm for their class and craft, this student's response was also a boon for the observation of an authentic 5E English language arts (ELA) lesson. On the other hand, we consider reactions from other students who participated in a lesson designed and delivered utilizing direct instructional methods: boredom, disinterest, and disengagement.

This article reviews implementation and outcomes of ELA lessons designed using authentic instruction (AI), a student-centered approach in which students and teachers share the focus as they engage in prior knowledge and experiences, explore relevant content, explain new understandings, extend their thinking to other situations, and evaluate their own learning, and a direct instruction (DI) approach, often teacher-centered and lecture-based, in two suburban high school ELA classrooms. Since AI and DI represent two distinct learning experiences commonly found in secondary classrooms, we focused on these two instructional approaches. Though the $5 \mathrm{E}$ model (engage, explore, explain, extend, evaluate) of lesson design is traditionally employed in the sciences, secondary ELA content and pedagogy are featured as the focus of this research. In consideration of teachers' curricular scope and sequence, we designed and observed the implementation of AI and DI lessons aligned with the school district's curriculum and state standards. As outside observers, we spent time with the teachers and students as they engaged in authentic and direct lessons and attempted to discover if and how two conditions (AI and DI) might affect students cognitively and emotionally. 
Before detailing the specifics of our research processes, we first offer an overview of authentic teaching and learning tenets, an underutilized 5E (engage, explore, explain, extend, evaluate) model of lesson design in ELA settings, and student motivation and academic emotions. We then provide information about participants and setting, describe research procedures, present and discuss findings, and consider implications for stakeholders and ideas for future research.

Early stages of data collection and analysis processes revealed opposing student attitudes in response to the two approaches: authentic instruction (AI) and direct instruction (DI). Students expressed a preference for an AI approach and conveyed feelings linked to their motivation and engagement. In a setting where student engagement is seldom expressed, explicit statements from student to teacher of "Are we going to get to do the fun lesson today?" and implicit expressions of motivation and engagement through willing whole group responses and small group collaboration showed a more significant impact on students' social and emotional approaches to learning in this lesson.

\section{LITERATURE REVIEW}

For the purposes of our research, and in consideration of recursive research processes, we narrowed our focus to consider primarily the AI approach both in the review of literature and in the research questions. We use DI as the standard approach, with the general assumption that DI is utilized in classrooms as a result of teachers, particularly novice, faced with navigating the challenges of the profession (Davis et al., 2006; Fantilli and McDougall, 2009), to better understand how students receive instruction, but we do not intend to present $\mathrm{AI}$ and DI as equivalent. The DI approach traditionally requires few resources and little preparation and is often utilized as a "fall back" for teachers who find that they are similarly low on time (von der Embse and Putwain, 2015; Lee and Hannafin, 2016). In an era of accountability where content coverage is frequently valued more than the learning experience itself, we seek to show than an AI approach is more effective than and as accessible as a DI approach. Moving forward, we view AI approaches through the lens of authentic teaching and learning and the $5 \mathrm{E}$ lesson design model.

\section{Authentic Teaching and Learning}

Authentic teaching and learning is guided by worthwhile and substantive objectives. Our research was shaped by the contention that innovative instruction and the means by which the instruction is structured might work toward authentic student engagement and achievement. In lessons and classrooms, the word authentic has been used in the way that Newmann and Wehlage (1993) intended: student achievement is meaningful and significant rather than pointless and inconsequential. Other researchers (Splitter, 2009; Preus, 2012; Garrett et al., 2016; Rubin et al., 2017) have considered how the authenticity framework influences teachers and students, and we aim to similarly explore this concept with particular regard to an AI approach.
Considering Newmann's work on authentic instruction, we relied on the following criterion to structure our ends: construction of knowledge, disciplined inquiry, value beyond school, and student-centered learning (Newmann and Wehlage, 1993; Newmann et al., 1995, 1996). These four interconnected components of authentic teaching and learning provide a framework for what students do and what teachers support during authentic instructional activities.

\section{Construction of Knowledge}

This characteristic relies on measured use of higher-order thinking (HOT) and mindfulness of depth of knowledge (DOK). HOT occurs when students utilize critical thinking to interpret and manipulate information to solve questions or problems; alternatively, lower-order thinking involves practices such as memorization and regurgitation of previous knowledge (Newmann, 1990; Fischer et al., 2011; Fern and Salleh, 2016). HOT requires students to work with ideas in novel ways to solve problems and discover new meanings. Inquiry resulting from engagement in HOT often leads to deeper knowledge. DOK is high when fewer topics are covered on a deeper level; it is inhibited when many concepts are covered superficially.

As students construct their own knowledge and understanding, they synthesize, generalize, explain, and analyze a variety of information. Throughout these processes, the teacher collaboratively facilitates manipulation of information and ideas and the students' construction of new understanding (Newmann et al., 1995). Research demonstrates in inquiry-based learning situations in science classrooms that engaging in HOT enhances student cognitive activity (Marshall and Horton, 2011; Saido et al., 2017). Additionally, HOT allows students, in English language arts courses, to engage in critical social justice literacy practices as they make text-to-text, text-to-self, and text-to-world connections (Boyd, 2017). In consideration of construction of knowledge, authentic learning is supported when the teacher serves as a guide and students have relative procedural and cognitive autonomy in the classroom.

\section{Disciplined Inquiry}

This tenet consists of students' prior knowledge, a focus on indepth understanding, and elaborated communication through substantive conversation (Newmann et al., 1996). Substantive conversation is high when there is extensive interaction about the ideas of content and the conversation includes higher-order thinking that results in questions raised, as opposed to repeating facts. It is inhibited when the teacher relies solely on lecture or does not facilitate the sharing of student ideas beyond a controlled script. Disciplined inquiry thrives when students lead conversations, including many voices and perspectives.

Engaging in disciplined inquiry, students make distinctions, raise questions, hypothesize, reason, debate, and support their opinions. Teachers support student conversation by asking meaningful questions. As students engage in sustained conversation, the teacher encourages students to share ideas through dialogue as they work toward a collective understanding. Comparable to the social studies classroom (Saye, 2017), ELA teachers must support beginners to the process of 
disciplined inquiry as they move toward natural and comfortable perception mastery. Furthermore, to help students understand the problematic nature of some concepts, teachers might organize lessons using essential questions to focus students on a single topic (Newmann et al., 1995). In accordance with authentic learning, as students develop ideas, choose from a variety of processes, justify their beliefs, generate new knowledge, and evaluate what and how they learned, they remain at the center of the learning activities.

\section{Value Beyond School}

This component measures the degree to which instruction has value and significance beyond the classroom. The extent to which a student is able to perceive connectedness of their instruction to the world can be discerned through distinguishing a clear connection between content and real-world problems or personal, lived experiences. Value beyond school is inhibited when there is no justification for the content outside of the classroom beyond the need to perform well for the course.

To promote value beyond school, students communicate, advocate, apply ideas, assist one another, perform, and create products. Teachers, then, are sure to connect to students' actual experiences or situations as they support exploration that allows for personal meaning and significance (Newmann et al., 1995). Real world applications are ideal, as "student accomplishment should have value beyond being an indicator of success in school" (Newmann et al., 1996, p. 284). Moreover, many researchers (see Quigley, 2014; Kirk-Kuwaye and Sano-Franchini, 2015; Hulleman et al., 2017) point to the need for in and out of school learning situations where students connect what they do in classrooms to their own lives. Authentic learning is optimal when instruction is connected to personal experiences, when it allows students to bring their prior knowledge and cultural background to the learning experience, and when the teacher actively encourages students to be agentic in procedural decision making.

\section{Student-Centered Learning}

This concept involves an approach in which the teacher serves as guide and students have relative procedural and cognitive autonomy in the classroom. Connected to value beyond school, student-centered learning is optimal when instruction is connected to personal experiences and needs and when it allows students to bring their prior knowledge and cultural background to the learning experience. In addition, it is high when the teacher actively encourages students to be active in procedural decision making. Student-centered learning is inhibited when instruction focuses on the needs of the curriculum (instead of the needs of the students) and when the teacher has full control over the direction and pace of instruction.

Lee and Hannafin (2016) state that student-centered learning is "neither rigidly prescribed nor strictly externally structured. Learning environments focus on knowledge acquisition, individual's reasoning, and understanding of key concepts" (p. 711). Teachers should allow for student ownership and focus on their personal experiences (Dewey, 1938; Estes, 2004; Brown, 2008; Overby, 2011; McElhany, 2017). Supporting students' use of prior knowledge, teachers share control with students and allow and encourage student autonomy.

Next, we explore one particular framework to foster authentic learning: the $5 \mathrm{E}$ model for lesson design.

\section{E Lesson Design in English Language Arts}

Uhrmacher et al. (2013) discuss the significance of lesson planning: "the process of lesson planning is an important part of the educational process that warrants much more attention" (p. 23). In this study, we focus on a model of lesson design prevalent in the sciences but less explored in ELA settings. Though 5E lesson design-crafted by the Biological Sciences Curriculum Study (BSCS) in the late 1980s-has been employed in science classrooms for decades, little research examines the model's implementation in ELA classes. The 5E model consists of five phases: Engage, Explore, Explain, Extend, and Evaluate. Moving through each phase recursively, students and teachers make connections to prior knowledge and experiences and become engaged in the content; actively explore concepts through shared experiences; begin to explain new understandings through process-oriented formative assessments; practice using new knowledge as they extend their learning to unique contexts and situations; and evaluate their current conceptions and learning processes and products.

Increased student mastery and interest is often reported when 5E lessons are implemented with high fidelity in inquiry-based science lessons (Bybee et al., 2006). While research similar to Niederberger (2009) focuses on literacies such as reading and writing in science curriculum, the explicit usefulness of the 5E model in ELA is less known. Bybee (2014) specifically addresses the science education community as he acknowledges the widespread use and effectiveness of this model. Other researchers have studied successes of 5E lesson design (Goldston et al., 2010, 2013; Anil and Batdi, 2015; Sickel and Friedrichsen, 2015) as well as the writing experiences of students in the science classroom (Wilcox and Jeffery, 2014). Our research serves as a starting point for extending the conversation to other content areas as well, including ELA.

ELA lessons developed and enacted using the authenticity and 5E frameworks and adhering to an AI approach can offer students experiences in which they engage and explore relevant content through substantive conversation, explain - to themselves, their peers, and their teacher-their understanding, extend newly constructed knowledge through application, and then evaluate what and how they learned. Alternatively, DI approaches to lesson design and delivery might focus primarily on the teacher introducing content, providing necessary information to students, and then requiring students to demonstrate understanding of the material. Our research centers on these two types of lesson design and teaching delivery as we explore the outcomes of AI and DI approaches, including student motivation and academic emotion.

\section{Student Motivation}

Motivation is an integral factor to consider when exploring student experience in the classroom. We define motivation as the process of how goal directed behavior is initiated and 
sustained (Ormrod, 2016). More specifically, in this research we investigated academic pressure and classroom mastery.

\section{Academic Pressure}

An important component of student motivation is students' critical thinking and depth of processing related to the material (Bong, 2008). Therefore, academic pressure exists when teachers press students to think deeply about content and thus are more likely to engage in critical thinking patterns. When students think critically, motivation (Donald, 1999) and achievement (Dwyer et al., 2014) have been shown to increase. Authentic instruction makes connections between content to experiences that students could have in everyday life. It follows that these connections would elicit critical thinking and deep engagement. Thus, we investigated the extent to which students perceived their instructors pressed them to think critically about target content.

\section{Classroom Mastery}

Researchers suggest that students hold specific goals toward learning (Covington, 2000; Grant and Dweck, 2003; Senko et al., 2011). Elliot and McGregor (2001) posit that students hold learning goals that are composed of two dimensions, including mastery and performance goals. Mastery goals occur when students desire to become competent with school content simply because they are interested and want to learn the material for learning's sake (Harackiewicz et al., 2002). Performance goals, on the other hand, occur when students want to show others (e.g., teacher, classmates) that they are competent in the content. Research shows that mastery goals are related to persistence (Wolters, 2004), achievement (Linnenbrink and Pintrich, 2002), and student interest (Urdan and Schoenfelder, 2006). We hypothesized that authentic instruction would increase perceived personal relevance and interest and thus increase students' perception that the class culture was encouraging mastery goals.

\section{Academic Emotions}

Emotions have become an essential component to investigate when considering students' experience with learning classroom content (Cross and Hong, 2012; Sinatra et al., 2014; Thein et al., 2015; Heddy et al., 2017; Pekrun et al., 2017). Emotions are defined as the labeling of psychophysiological feelings (Pekrun et al., 2002). More specifically, we define emotions in terms of Pekrun (2000) achievement emotions theoretical framework, which are emotions directly related to learning and school contexts. According to Pekrun (2006), achievement emotions have a positive (e.g., enjoyment, interest) or negative (e.g., frustration, boredom) valence. We explored emotions particular to specific ELA content: elements of an academic essay. Thus, we investigated topic emotions as described by Broughton and colleagues (Broughton et al., 2013). We chose two emotions in particular that we thought would be relevant to the topic and would represent opposite sides of the positive and negative emotion valence; we selected interest and boredom as representing positive and negative emotions, respectively. As authentic instruction promotes students' application of classroom content to real world contexts, we hypothesized that recognizing the usefulness of content would trigger interest and reduce boredom when compared to textbook-based instruction, which aligns with previous research exploring authentically designed instruction and its effect on academic emotions (Heddy and Sinatra, 2017; Heddy et al., 2017).

\section{RESEARCH QUESTIONS}

Based on our search of the literature, prior knowledge of the topic, and emergent research design and data, we developed the following research questions:

1) Would authentic instruction promote more motivation (academic pressure, class mastery) than direct instruction?

2) Would authentic instruction promote more interest and/or less boredom than direct instruction?

We hypothesized that AI would promote more perceived academic pressure, classroom mastery, and interest and less boredom than DI. Due to the need for authentic instruction in the ELA classroom (Whitney, 2011), we pursued these two research questions.

First, we postulated that AI would promote more motivation (defined as the process of how goal directed behavior is initiated and sustained) than DI, specifically through academic pressure and class mastery (Bong, 2008). Previous work has found AI enables students to form meaningful connections between content and their lived experiences, eliciting deeper engagement and HOT (Heddy and Sinatra, 2013). Additionally, AI supports student mastery goals, where students develop competence out of sheer interest rather than from pressure of competition or performance (Senko et al., 2011).

Furthermore, we hypothesized AI would promote more interest and less boredom than DI. In alignment with previous research we hypothesized that when students are able to construct their own knowledge with relative autonomy while finding significance beyond the classroom, their interest (Renninger and $\mathrm{Su}, 2012$ ) in instruction would increase and boredom (Heddy and Sinatra, 2017) would decrease.

\section{METHODS}

\section{Design}

The design for this study was a quasi-experimental pre and post intervention with two conditions. Participants in one condition received a multi-day lesson incorporating the tenets of authentic instruction based on the $5 \mathrm{E}$ theoretical framework (The authentic, student-centered lesson can be found on the K20 Center's LEARN website: http://bit.ly/ 2vMduU4. Participants in the other condition received a multiday direct instructional technique. Approximately half of the classes were randomly selected into each of the conditions. The independent variable was the type of instruction implemented (authentic and direct). The dependent variables were measures of emotion (interest and boredom) and student motivation (academic pressure and classroom mastery). Before describing the participants and context, we offer an overview of both conditions: the authentic $5 \mathrm{E}$ instruction (AI) and the direct instruction (DI). 


\section{Condition 1: Authentic 5E Instruction}

Of the two conditions utilized, the authentic approach engaged students in multiple independent and group strategies to both identify and analyze essential structural elements of an essay. In turn, the goal of the lesson was for students to both practice and gain and clearer perspective of how to write essays for a range of audiences and purposes with greater clarity and effectiveness. The lesson, titled "Seeing the BIG Picture: Incorporating thesis, evidence, elaboration, and concluding statements in your essay" is structured according to the 5Es: Engage, Explore, Explain, Extend, and Evaluate.

As an engagement activity, students worked both individually and collaboratively with peers to activate prior knowledge and form new connections between terms (introduction, thesis, details, elaboration, commentary, paraphrasing, summarizing, conclusion, etc.) related to the elements of an essay. Using an authentic, research-based strategy, students composed individual summaries explaining how the terms displayed fit together to form a cohesive view of an essay.

Students explored these concepts as they analyzed a set of sentence strips that reflected various technical parts of an essay. Working in groups, students used their prior knowledge and new connections formed during the Engage discussion to organize the strips into a cohesive essay outline. To reflect on their organizational process, students collaboratively recorded observations and questions about the typical arrangement of elements of an essay.

In order to explain their understandings, students read and examined a "snapshot" of a passage of an informative essay. In a similar structure to the Explore sentence strips, students were tasked with collaboratively organizing the thesis, evidence, and concluding statements of portions of informative essays ranging from the accomplishments of Julius Caesar to Ray Bradbury's use of suspense. While working with these passages, students used annotating strategies to note the significance and rationale behind the organization of the essay pieces. Next, students were actively involved with their assigned passages by composing their own elaboration and commentary for each piece of evidence provided in their passage "snapshot."

As an extension, students revisited the strategy used in the Engage stage to revise and extend their initial summaries. To evaluate students' learning, the teacher collected students' responses for a formative assessment to gauge students' understanding of the elements and construction of an essay before moving forward. Ultimately, in the authentic condition, students worked both individually and collaboratively with the teacher acting primarily as a facilitator of student learning rather than purveyor of information.

\section{Condition 2: Direct Instruction}

In addition to the authentic lesson, we crafted a lesson utilizing direct instruction focusing on elements of an essay including thesis statements, supporting evidence, elaboration, and concluding statements. Throughout the lesson, the teacher served as a disseminator of information and knowledge while students took on a passive role with little room for collaboration, inquiry, or exploration.
To begin the lesson, the teacher distributed guided notes for students to complete as she lectured. Using a PowerPoint presentation, the teacher walked students first through information about thesis statements. After students took notes on this information, they were provided several examples of appropriate thesis statements. To practice what they had learned, students viewed three "snapshots" of essays and individually crafted potential thesis statements that could be integrated into an introductory paragraph. Though students worked independently, a few shared out their statements with the whole class with the teacher's encouragement.

The lesson then moved toward an explanation of supporting evidence through paraphrases and direct quotations, including how to appropriately embed quotations in one's writing. Again, students took notes on the guided note-catcher provided over these concepts before practicing embedding quotations.

Next, information about elaborating was discussed, primarily in lecture form guided by the PowerPoint presentation from the teacher, as students took notes about developing details to support main ideas and explaining evidence and how it supports students' thesis statement or key points. Students were also instructed to include original insights, explanations, and interpretations to adequately elaborate on evidence. To practice elaboration, students were provided evidence in the form of direct quotations and paraphrases and asked to elaborate on the evidence.

Finally, students took notes over concluding statements and viewed several examples of appropriate concluding statements. No independent practice occurred during this portion of the lesson, though students did interact with the examples by discussing what they noticed and wondered as well as pointing to effective uses of transitional words and phrases.

\section{Participants/Context}

Two female English teachers at a suburban high school in the mid-south agreed to participate in our research. Both teachers taught English II to high school sophomores; one teacher taught six sections while the other taught three. 237 students total engaged in the lessons across the nine sections. After a random assignment by section, 101 students participated in one condition (DI) while 136 students participated in the other condition (AI). Total enrollment at the suburban high school was 2,644 students, with $80 \%$ of the student population identifying as Caucasian, $8 \%$ as Hispanic, 6\% Black, 4\% Asian, and 2\% Native American. Moreover, $18 \%$ of students qualified for free and reduced lunch.

\section{Instruments \\ PALS}

We used items from Patterns of Adaptive Learning Scales (PALS) - specifically, academic pressure and classroom mastery (Midgley et al., 2000). Using five-point Likert-type scales (Midgley et al., 2000), PALS uses goal orientation theory to study student behavior, affect, and motivation. We thought those components would be most salient in consideration of an authentic teaching and learning framework and that authentic teaching would lead to mastery and critical thinking (academic 
pressure). These scales supported necessary components of authentic instruction.

Academic pressure was used to gauge students' perceptions that they are pressed by their teacher for understanding. Using the same Likert scale ranging from (1) "not at all true" to (5) "very true," student participants responded to academic pressure items (e.g., "I'm certain I can master the skills taught in class this year"). Cronbach's alpha was $\alpha=0.83$, which suggests that the items were reliable.

Another PALS subscale used was classroom mastery. Students responded to items that referred to their perceptions that academic engagement in the classroom is oriented toward developing content competence (e.g., "In our class, trying hard is very important"). Students ranked all classroom mastery items on a Likert scale from (1) "not at all true" to (5) "very true." Cronbach's alpha was $\alpha=0.79$, which suggests that the items were reliable.

As discussed in the review of literature, authentic instruction, and learning is guided by worthwhile and substantive objectives. Classroom mastery in which students were able to perceive the connection between their academic engagement and content competence aided students in constructing knowledge. The authenticity components of disciplined inquiry and student-centered learning were both gauged through academic pressure measurement.

\section{Emotions Survey}

A modified instrument based on prior research conducted by Broughton and colleagues (Broughton et al., 2013) measured participants' topic emotions related to ELA content. The instrument asked students to rate the intensity that they were experiencing two emotions including interest and boredom. We chose these specific emotions by hypothesizing which emotions would be most relevant when learning about our specific lesson focusing on elements of an essay. Furthermore, we posited that interest and boredom would adequately represent near opposite sides of a positive and negative emotional valence. The scale utilized a 5-point Likert scale ranging from "not at all" (1) to "very strong" (5) as the anchors. We implemented the emotions survey at pre and post intervention. Cronbach's alpha was $\alpha=$ 0.69 , which suggests that the items were in the acceptable range of reliability.

\section{Procedures}

At the onset of our research project, a recruitment flier was distributed to a group of educators (district administrators, curriculum coordinators, building principals, and teachers) who helped identify teachers actively engaged in teaching high school ELA courses. Once a cooperating school site was established, we collaborated with the suburban high school to provide an overview of the project, obtain a letter of support/data sharing agreement to have access to de-identified student data, and identify teachers who might participate in the study. Both English teachers who agreed to participate were provided and voluntarily completed a signed consent form. Similarly, students in their classes voluntarily provided informed consent (All students were 16 years of age or older; therefore, parental consent was not obtained). Each teacher supplied her participating sections and the number of students currently enrolled; each section was then assigned a random identification number. We randomly assigned each section (without a linkage to teachers) to one of the two conditions.

Based on the randomized assignment, the teacher was provided a lesson plan to implement with designated sections. Both teachers were asked to teach an AI and DI lesson to the corresponding sections. We offered support to each teacher through site visits to review the lesson, discuss the instructional strategies/processes employed to deliver the content, and provide resources/materials required for the lesson. As part of the lesson, all students completed a pre-survey-identical for both conditions-to gain insight into their current emotions and motivation.

The teacher then implemented the AI/DI lesson as assigned with each section. We observed the teachers' implementation and completed fields notes focusing on fidelity of implementation for both lessons. After the lesson, students completed a post-survey to measure emotions and motivation.

\section{FINDINGS}

\section{Data Screening and Descriptive Statistics}

All skewness and kurtosis values were less than or equal to an absolute value of 3 , indicating that we could assume normality in the remainder of the analyses (Tabachnick et al., 2001). Furthermore, no outliers were found in any of the data (i.e., zs $\leq 3)$. All reported tests are two-tailed. All data screening techniques, descriptive statistics, and advanced statistical analysis were conducted using the SPSS 21 software.

Differences between conditions were investigated by implementing an independent sample $t$-test on the pretest measures including the PALS instrument and topic emotions surveys. Pretest scores did not differ between the conditions. These results suggest it could be assumed that there were no significant differences between conditions that may skew results. That is, equality could be assumed between the treatment and comparison condition with regard to the pretest instruments. We next share findings for student motivation (academic pressure, class mastery) and emotions (interest, boredom). See Table 1 for a summary of the findings.

\section{Motivation Findings}

To address the first question, Would authentic instruction promote more motivation (academic pressure, class mastery) than direct instruction? repeated measures analysis of variance (ANOVA) was conducted on each PALS sub construct. For academic pressure, a repeated measures analysis of variance (ANOVA) was conducted with time used (pretest to posttest on the academic pressure subscale) as the within-subjects factor and group (treatment and comparison) as the between-subjects factor. A Box's $M$ test for unequal group sizes indicated that our assumption of equality of the variance-covariance matrices was met (Box's $M=8.10, p=0.046$ ). Box's $M$ indicates non-robust results if significant at the.001 level (Tabachnick et al., 2001). The results of the repeated measures ANOVA revealed that the 
TABLE 1 | Descriptive statistics academic pressure, class mastery, interest, and boredom (pre to post) between groups ( $N=237$ ).

\begin{tabular}{|c|c|c|c|c|c|c|c|c|}
\hline & \multirow[b]{2}{*}{ Statistic } & \multicolumn{2}{|c|}{ Treatment } & \multicolumn{2}{|c|}{ Comparison } & \multicolumn{3}{|c|}{ Statistics } \\
\hline & & Pre & Post & Pre & Post & $\boldsymbol{F}$ & $p$ & $n^{2}$ \\
\hline \multirow[t]{2}{*}{ Academic pressure } & Mean & 3.39 & 3.49 & 3.49 & 3.40 & 4.87 & $=0.028$ & 0.023 \\
\hline & $\mathrm{SD}$ & 0.76 & 0.76 & 0.76 & 0.73 & & & \\
\hline \multirow[t]{2}{*}{ Class mastery } & Mean & 3.76 & 3.73 & 3.94 & 3.74 & 5.40 & $=0.021$ & 0.026 \\
\hline & $\mathrm{SD}$ & 0.85 & 0.73 & 0.68 & 0.76 & & & \\
\hline \multirow[t]{2}{*}{ Interest } & Mean & 3.21 & 3.15 & 3.13 & 2.61 & 10.89 & $=0.001$ & 0.05 \\
\hline & $\mathrm{SD}$ & 1.04 & 1.09 & 0.99 & 0.96 & & & \\
\hline \multirow[t]{2}{*}{ Boredom } & Mean & 2.93 & 2.89 & 3.09 & 3.36 & 4.70 & $=0.03$ & 0.022 \\
\hline & $\mathrm{SD}$ & 1.13 & 1.09 & 1.07 & 1.03 & & & \\
\hline
\end{tabular}

interaction between time and group was significant, $F_{(1,206)}=$ 4.87, $p=0.028, \eta^{2}=0.023$. The effect size was small. According to Tabachnick et al. (2001) when using partial eta squared 0.01to-0.05 is a small effect; $0.06-0.13$ is a moderate effect, and 0.14 and above is considered a large effect. A paired samples $t$ test was conducted to determine if the difference between the means was significant at pretest and posttest for both conditions independently. The t-statistic for the AI condition (Pretest $M=$ $3.39, S D=0.76$, Posttest $M=3.49, S D=0.76$ ) was significant, $t$ $(119)=2.52, p=0.013$. The t-statistic was not significant (Pretest $M=3.49, S D=0.76$, Posttest $M=3.40, S D=0.73$ ) for the DI condition, $t(93)=0.761, p=0.449$. These results suggest that the AI condition saw an increase in perceived academic pressure, whereas the DI condition saw no change in perceived academic pressure.

For class mastery, time was used (pretest to posttest on the class mastery subscale) as the within-subjects factor and group (treatment and comparison) as the between-subjects factor. A Box's $M$ test for unequal group sizes indicated that our assumption of equality of the variance-covariance matrices was met (Box's $M=5.24, p=0.159$ ). The results of the repeated measures ANOVA revealed that the interaction between time and group was significant, $F_{(1,205)}=5.40, p=0.021, \eta^{2}=0.026$. The effect size was small. A paired samples $t$-test was conducted to determine if the difference between the means was significant at pretest and posttest for both conditions independently. The t-statistic for the AI condition (Pretest $M=3.76, S D=0.85$, Posttest $M=3.73, S D=0.73$ ) was not significant, $t_{(114)}=0.851$, $p=0.397$. The t-statistic was significant (Pretest $M=3.94, S D$ $=0.68$, Posttest $M=3.74, S D=0.76$ ) for the DI condition, $t_{(91)}$ $=3.89, p<0.001$. These results suggest that the AI condition saw no change in perceived class mastery, whereas the DI saw a significant decrease.

\section{Emotions Findings}

To address the second question, Would authentic instruction promote more interest and/or less boredom than direct instruction? a repeated measures analysis of variance (ANOVA) was conducted using time (pretest to posttest on the interest variable) as the within-subjects factor and group (AI and DI) as the between-subjects factor. A Box's $M$ test for unequal group sizes indicated that our assumption of equality of the variancecovariance matrices was met (Box's $M=1.96, p=0.585$ ). The results of the repeated measures ANOVA revealed that the interaction between time and group was significant, $F_{(1,210)}=$ 10.89, $p=0.001, \eta^{2}=0.05$. The effect size was moderate. A paired samples $t$-test was conducted to determine if the difference between the means was significant at pretest and posttest for both conditions independently. The t-statistic for the AI condition (Pretest $M=3.21, S D=1.04$, Posttest $M=3.15, S D=1.09$ ) was not significant, $t_{(119)}=0.630, p=0.53$. The t-statistic was significant (Pretest $M=3.13, S D=0.99$, Posttest $M=2.61, S D$ $=0.96$ ) for the DI condition, $t_{(91)}=4.95, p<0.001$. These results suggest that the AI condition saw no change in reported interest, whereas the DI saw a decrease in interest.

For boredom, a repeated measures analysis of variance (ANOVA) was conducted with time used (pretest to posttest on the boredom variable) as the within-subjects factor and group (AI and DI) as the between-subjects factor. A Box's $M$ test for unequal group sizes indicated that our assumption of equality of the variance-covariance matrices was met (Box's $M=0.83, p=$ 0.844). The results of the repeated measures ANOVA revealed that the interaction between time and group was significant, $F_{(1,211)}=4.70, p=0.03, \eta^{2}=0.022$. The effect size was small. A paired samples $t$-test was conducted to determine if the difference between the means was significant at pretest and posttest for both conditions independently. The t-statistic for the AI condition (Pretest $M=2.93, S D=1.13$, Posttest $M=2.89, S D=1.09$ ) was not significant, $t_{(118)}=0.417, p=0.678$. The t-statistic was significant (Pretest $M=3.09, S D=1.07$, Posttest $M=3.36, S D$ $=1.03$ ) for the DI condition, $t_{(93)}=2.63, p=0.01$. These results suggest that the AI condition saw no change in boredom, whereas the DI saw a significant increase in boredom.

\section{DISCUSSION}

\section{Summary of Findings}

Our analyses found that there was a significant increase in academic pressure in the authentic (AI) condition and no change in the direct (DI) condition; furthermore, we found a decrease in classroom mastery in the DI condition and not the AI condition. With regard to emotions, there was no change in boredom in the 
AI condition, but there was an increase in boredom in the DI condition. There was no change in interest in the AI condition but a significant decrease in interest in the DI condition. These results have both theoretical and practical implications with regard to the constructs of English education.

\section{Implications}

In consideration of our findings, and in connection to relevant literature, we specifically consider implications for academic pressure, classroom mastery, and student emotions. These concepts connect explicitly to teacher education programs, practicing teachers, and pre-service teachers.

\section{Academic Pressure}

The results of this study have significant implications for academic pressure in the ELA classroom. Of the two groups who received the instruction, the DI condition reported no change in perceived academic pressure. The group receiving the AI condition reported a significant increase in perceived academic pressure. Authentic and meaningful instruction challenges students to connect classroom instruction to experiences that they will encounter outside of school (Bong, 2008). The implications of these results for teachers are indicative of the need for instruction that presses students to think deeply and critically about the content presented. Teachers, therefore, might construct learning opportunities that allow students to engage meaningfully with relevant content.

The finding that the AI condition yielded significant increase in perceived academic pressure is a positive discovery that aligns with previous research. As predicted, students who experienced the DI lesson did not perceive that their teacher pressed them to thinking deeply about the content presented. The DI lesson was heavily teacher guided, with little room for student autonomy that facilitated personal connections. While this direct form of instruction did not elicit deep engagement from students, the implementation of a $5 \mathrm{E}$ lesson utilizing the authenticity framework allowed students to connect the instruction to their everyday life. Theoretically, the implications suggested by research concerning academic pressure (Donald, 1999; Dwyer et al., 2014) are that as students think critically, their motivation and achievement increase. These complement the practical implications, which suggest that when teachers utilize the $5 \mathrm{E}$ model and authenticity framework in the ELA classroom, students form deeper connections to the content as a result of feeling challenged further to think of how content relates to their prior knowledge, daily life experiences, and future goals.

\section{Classroom Mastery}

When comparing pre and post conditions across the two distinct types of instructional methods, we found no change in perceived classroom mastery in the DI condition but a significant decrease in perceived classroom mastery in the AI condition. This suggests that authentic instruction can impact the ELA classroom in several ways. First, if we desire students to perceive academic engagement oriented toward developing competence with ELA content, creating authentic learning experiences is paramount. When students encounter direct methods of instruction, their perceived classroom mastery is likely to decrease. Students' perceptions of teacher and class culture might negatively affect mastery goals (Covington, 2000; Grant and Dweck, 2003; Senko et al., 2011). In turn, in these learning experiences, students might not perceive lessons as increasing relevance and interest.

Though the AI group did not experience an increase in class mastery, the DI group's perception of class mastery did significantly decrease. This has practical implications that demonstrate the negative results on direct instruction and lesson design. With the implementation of only one lesson, though class mastery did not increase in the authentic 5E lesson, it did remain consistent. As $5 \mathrm{E}$ lessons incorporating components of authenticity are implemented on a consistent basis, students might perceive both the class culture and the teacher promoting mastery goals. This could increase students' desire to become competent through an authentic interest in ELA content.

\section{Emotions}

Considering students' emotions toward learning and school contexts-especially interest and boredom-in connection to the ELA classroom and the two lessons, there are specific implications related to both. The group which received the DI lesson experienced a decrease in interest and an increase in boredom. These results have implications for ELA teachers in terms of lesson design and implementation. Direct instruction might decrease student interest and increase their boredom; therefore, if we aim to maintain student interest and decrease the likelihood of students becoming bored, we should consider designing lessons that align with the authenticity framework (Hidi and Renninger, 2006; Pekrun and LinnenbrinkGarcia, 2012). That is, lessons should promote higher order thinking, substantive conversation, connections beyond the classroom, and student-centered learning. Moreover, these lessons might be structured using the 5E lesson design in which students engage with relevant content, explore concepts, explain their new knowledge, extend their understanding, and evaluate their learning. Using the authenticity framework in combination with the $5 \mathrm{E}$ model, students might maintain a high level of interest, and their boredom might not increase (Renninger and Su, 2012).

Importantly, the AI group did not experience a change in either interest or boredom. However, a high level of interest was maintained in the AI group as it decreased in the DI group. These findings suggest that student interest can continue when authentic, meaningful lessons designed using the 5E model for lesson design are implemented in an ELA setting.

\section{Limitations}

We understand that instructional approaches vary in practicality and effectiveness across grade levels, content areas, and various settings, and, though we consider two distinct (and often perceived as dichotomous) approaches to teaching and learning, we understand that context matters. Also, we recognize that participants in this study are not representative of teachers and students across the nation or world. This suburban school site included primarily Caucasian students from upper middleclass families. Thus, not all students would experience the 
lesson in the same way as those in this study. In addition, one of the groups consisted of Pre-Advanced Placement students, who represent a specific demographic of high achieving students. Finally, the two teachers who agreed to participate in our study were eager to engage in the authentic approach; therefore, their general pedagogical decisions outside of this study were likely more aligned with AI. The DI approach was, in some ways, disconnected from these teachers' regular practices.

As practitioner scholars, we understand that a lesson plan is often implemented in a variety of ways according to teacher and student needs and unique contextual factors. Even authentic lessons on paper might not be presented in the most authentic way in reality. Recognizing this limitation, our field notes attempted to describe areas in which teachers implemented the lesson with high and low fidelity.

Finally, although each lesson spanned multiple days, our study may be limited due to brevity of implementation. Constructs like classroom mastery and motivation might be more useful when considered over time and not just in one lesson.

\section{Future Directions}

Though this project offered a glimpse into an authentic learning situation, future research can shed light on how the $5 \mathrm{E}$ model of lesson design could be implemented in an ELA classroom. Moving forward, research might extend beyond one lesson and move toward a unit of study. A longitudinal study could provide further insight into how student emotions and content knowledge is affected when comparing direct instruction to authentic instruction. Though there is more work to be done, we have begun the process of making authenticity and the $5 \mathrm{E}$ model of lesson design more apparent in ELA classrooms in hopes that a variety of stakeholders benefit both now and in the future.

\section{CONCLUSION}

We hope this research can encourage researchers and teachers in a range of content areas and grade levels to engage in authentic teaching and learning practices through the $5 \mathrm{E}$ model of lesson design to benefit students in a variety of ways. Student

\section{REFERENCES}

Anil, Ö., and Batdi, V. (2015). A comparative meta-analysis of 5E and traditional approaches in Turkey. J. Educ. Train. Stud. 3, 212-219. doi: 10.11114 /jets.v3i6.1038

Bong, M. (2008). Effects of parent-child relationships and classroom goal structures on motivation, help-seeking avoidance, and cheating. J. Exp. Educ. 76, 191-217. doi: 10.3200/JEXE.76.2.191-217

Boyd, A. S. (2017). Social Justice Literacies in the English Classroom. Teachers College, Columbia University.

Broughton, S. H., Sinatra, G. M., and Nussbaum, E. M. (2013). "Pluto has been a planet my whole life!" Emotions, attitudes, and conceptual change in elementary students learning about Pluto's reclassification. Res. Sci. Educ. 43, 529-550. doi: 10.1007/s11165-0119274-x

Brown, J. K. (2008). Student-centered instruction: involving students in their own education. Music Educ. J. 94, 30-35. doi: 10.1177/00274321080940050108 motivation and emotions can increase when teachers focus on authentic instruction, including construction of knowledge, disciplined inquiry, value beyond school, and student-centered learning. Alternatively, motivation and emotions often decrease when direct methods are employed. Our research revealed the significance of authentic teaching and learning, and, though just a snapshot from two classrooms, offers insight into how teachers and students are positively affected by these practices.

\section{DATA AVAILABILITY}

The datasets generated for this study are available on request to the corresponding author.

\section{ETHICS STATEMENT}

The studies involving human participants were reviewed and approved by the University of Oklahoma Institutional Review Board with written informed consent from all subjects. All subjects gave written informed consent in accordance with the Declaration of Helsinki. The protocol was approved by the University of Oklahoma Institutional Review Board. Written informed consent to participate in this study was provided by the participants' legal guardian/next of kin.

\section{AUTHOR CONTRIBUTIONS}

GJ and JB conducted research in the field (including data collection) and wrote sections of the manuscript. BH analyzed the data and wrote sections of the manuscript. SW, LW, LA, SD, and GG collaborated with GJ, JB, and BH in the conceptual design of the study and the execution of protocols and procedures. All authors contributed to manuscript revision and read and approved the submitted version.

\section{FUNDING}

Publication of this article was funded in part by the University of Florida Open Access Publishing Fund.
Bybee, R. W. (2014). The BSCS 5E instructional model: Personal reflections and contemporary implications. Sci. Child. 51, 10-13. Retrieved from: http://search. ebscohost.com/login.aspx?direct=true \&AuthType=ip, uid \&db=edsgao\&AN= edsgcl.377575190\&site=eds-live

Bybee, R. W., Taylor, J. A., Gardner, A., Van Scotter, P., Powell, J. C., Westbrook, A., et al. (2006). The BSCS 5E instructional model: origins and effectiveness. Colo. Springs Co BSCS 5, 88-98. Available online at: http://www.fremonths.org/ ourpages/auto/2008/5/11/1210522036057/bscs5efullreport2006.pdf

Covington, M. V. (2000). Goal theory, motivation, and school achievement: an integrative review. Annu. Rev. Psychol. 51, 171-200. doi: 10.1146/annurev.psych.51.1.171

Cross, D. I., and Hong, J. Y. (2012). An ecological examination of teachers' emotions in the school context. Teach. Teach. Educ. 28, 957-967. doi: 10.1016/j.tate.2012.05.001

Davis, E. A., Petish, D., and Smithey, J. (2006). Challenges new science teachers face. Rev. Educ. Res. 76, 607-651. doi: 10.3102/00346543076004607

Dewey, J. (1938). Experience and Education. Macmillan, New York, NY. 
Donald, J. G. (1999). Motivation for higher-order learning. N. Dir. Teach. Learn. 1999, 27-35. doi: 10.1002/tl.7803

Dwyer, C. P., Hogan, M. J., and Stewart, I. (2014). An integrated critical thinking framework for the 21st century. Thinking Skills Creativity 12, 43-52. doi: 10.1016/j.tsc.2013.12.004

Elliot, A. J., and McGregor, H. A. (2001). A $2 \times 2$ achievement goal framework. J. Pers. Soc. Psychol. 80:501. doi: 10.1037//0022-3514.80.3.501

Estes, C. A. (2004). Promoting student-centered learning in experiential education. J. Exp. Educ. 27, 141-160. doi: 10.1177/105382590402700203

Fantilli, R. D., and McDougall, D. E. (2009). A study of novice teachers: challenges and supports in the first years. Teach. Teach. Educ. 25, 814-825. doi: 10.1016/j.tate.2009.02.021

Fern, C. C. S., and Salleh, U. K. M. (2016). "The emphasis of Higher Order Thinking (HOT) in the curriculum and the implementation in reality," in Knowledge, Service, Tourism \& Hospitality: Proceedings of the Annual International Conference on Management and Technology in Knowledge, Service, Tourism \& Hospitality 2015 (SERVE 2015), Bandung, Indonesia, 1-2 August 2015 (Bandung: CRC Press), 61. doi: 10.1201/b21184-13

Fischer, C., Bol, L., and Pribesh, S. (2011). An investigation of higher-order thinking skills in smaller learning community social studies classrooms. Am. Second. Educ. 5-26. Available online at: https://digitalcommons.odu.edu/efl_ fac_pubs $/ 38$

Garrett, L., Huang, L., and Charleton, M. C. (2016). A framework for authenticity in the mathematics and statistics classroom. Math. Educ. 25, 32-55. Available online at: https://files.eric.ed.gov/fulltext/EJ1110639.pdf

Goldston, M. J., Dantzler, J., Day, J., and Webb, B. (2013). A psychometric approach to the development of a $5 \mathrm{E}$ lesson plan scoring instrument for inquiry-based teaching. J. Sci. Teacher Educ. 24, 527-551. doi: 10.1007/s10972-012-9327-7

Goldston, M. J., Day, J. B., Sundberg, C., and Dantzler, J. (2010). Psychometric analysis of a $5 \mathrm{E}$ learning cycle lesson plan assessment instrument. Int. J. Sci. Math. Educ. 8, 633-648. doi: 10.1007/s10763-009-9178-7

Grant, H., and Dweck, C. S. (2003). Clarifying achievement goals and their impact. J. Pers. Soc. Psychol. 85:541. doi: 10.1037/0022-3514.85.3.541

Harackiewicz, J. M., Barron, K. E., Pintrich, P. R., Elliot, A. J., and Thrash, T. M. (2002). Revision of achievement goal theory: necessary and illuminating. J. Educ. Psychol. 94, 638-645. doi: 10.1037//0022-0663.94.3.638

Heddy, B. C., and Sinatra, G. M. (2013). Transforming misconceptions: using transformative experience to promote positive affect and conceptual change in students learning about biological evolution. Sci. Educ. 97, 723-744.

Heddy, B. C., and Sinatra, G. M. (2017). Transformative parents: facilitating transformative experiences and interest with a parent involvement intervention. Sci. Educ. 101, 765-786.

Heddy, B. C., Sinatra, G. M., Seli, H., Taasoobshirazi, G., and Mukhopadhyay, A. (2017). Transforming college success: making learning meaningful to at-risk students. Educ. Psychol. 37, 565-581.

Hidi, S., and Renninger, K. A. (2006). The four-phase model of interest development. Educ. Psychol. 41, 111-127. doi: 10.1207/s15326985ep4102_4

Hulleman, C. S., Kosovich, J. J., Barron, K. E., and Daniel, D. B. (2017). Making connections: replicating and extending the utility value intervention in the classroom. J. Educ. Psychol. 109:387. doi: 10.1037/edu0000146

Kirk-Kuwaye, M., and Sano-Franchini, D. (2015). "Why Do I Have to Take This Course?" How academic advisers can help students find personal meaning and purpose in general education. J. Gen. Educ. 64, 99-105. doi: 10.1353 /jge.2015.0008

Lee, E., and Hannafin, M. J. (2016). A design framework for enhancing engagement in student-centered learning: own it, learn it, and share it. Educ. Technol. Res. Dev. 64, 707-734. doi: 10.1007/s11423-015-9422-5

Linnenbrink, E. A., and Pintrich, P. R. (2002). Achievement goal theory and affect: an asymmetrical bidirectional model. Educ. Psychol. 37, 69-78. doi: 10.1207/S15326985EP3702_2

Marshall, J. C., and Horton, R. M. (2011). The relationship of teacher-facilitated, inquiry-based instruction to student higher-order thinking. Sch. Sci. Math. 111, 93-101. doi: 10.1111/j.1949-8594.2010.00066.x

McElhany, J. S. (2017). Awakening student ownership: transitioning to a student-centered environment. Art Educ. 70, 29-35. doi: 10.1080/00043125.2017.1247567
Midgley, C., Maehr, M. L., Hruda, L. Z., Anderman, E., Anderman, L., Freeman, K. E., et al. (2000). Manual for the patterns of adaptive learning scales. Ann. Arbor 1001, 48109-41259. Available online at: http://www.umich.edu/ pals/ PALS\%202000_V12Word97.pdf

Newmann, F. M. (1990). Higher order thinking in teaching social studies: a rationale for the assessment of classroom thoughtfulness. J. Curr. Stud. 22, 41-56. doi: 10.1080/0022027900220103

Newmann, F. M., Marks, H. M., and Gamoran, A. (1996). Authentic pedagogy and student performance. Am. J. Educ. 104, 280-312. doi: 10.1086/444136

Newmann, F. M., Secada, W. G., and Wehlage, G. (1995). A Guide to Authentic Instruction and Assessment: Vision, Standards and Scoring. Madison: Wisconsin Center for Education Research.

Newmann, F. M., and Wehlage, G. G. (1993). Five standards of authentic instruction. Educ. Leadersh. 50, 8-12.

Niederberger, S. (2009). Incorporating young adult literature into the $5 \mathrm{E}$ learning cycle. Middle Sch. J. 40, 25-33. doi: 10.1080/00940771.2009.11 461678

Ormrod, J. E. (2016). Teaching across rather than within theories of learning: a "big ideas" approach to organizing educational psychology courses. Chall. Innov. Educ. Psychol. Teach. Learn. 3-14.

Overby, K. (2011). Student-centered learning. ESSAI 9:32. Available online at: http://dc.cod.edu/essai/vol9/iss1/32

Pekrun, R. (2000). "A social cognitive, control-value theory of achievement emotions," in Motivational Psychology of Human Development, ed J. Heckhausen (Amsterdam: Elsevier Science B.V), 143-163. doi: 10.1016/S0166-4115(00)80010-2

Pekrun, R. (2006). The control-value theory of achievement emotions: assumptions, corollaries, and implications for educational research and practice. Educ. Psychol. Rev. 18, 315-341. doi: 10.1007/s10648-0069029-9

Pekrun, R., Goetz, T., Titz, W., and Perry, R. P. (2002). Academic emotions in students' self-regulated learning and achievement: a program of qualitative and quantitative research. Educ. Psychol. 37, 91-105. doi: $10.1207 /$ S15326985EP3702_4

Pekrun, R., Lichtenfeld, S., Marsh, H. W., Murayama, K., and Goetz, T. (2017). Achievement emotions and academic performance: longitudinal models of reciprocal effects. Child Dev. 88, 1653-1670. doi: 10.1111/cdev. 12704

Pekrun, R., and Linnenbrink-Garcia, L. (2012). "Academic emotions and student engagement," in Handbook of Research on Student Engagement, eds S. L. Christenson, A. L. Reschly, and C. Wylie (Boston, MA: Springer), 259-282. doi: 10.1007/978-1-4614-2018-7_12

Preus, B. (2012). Authentic instruction for 21st century learning: higher order thinking in an inclusive school. Am. Second. Educ. 40, 59-79.

Quigley, C. (2014). Expanding our view of authentic learning: bridging in and out-of-school experiences. Cult. Stud. Sci. Educ. 9, 115-122. doi: 10.1007/s11422-013-9535-2

Renninger, K. A., and Su, S. (2012). "Interest and its development," in The Oxford Handbook of Human Motivation, ed R. M. Ryan (Oxford: Oxford University Press), 167-187.

Rubin, B. C., Ayala, J., and Zaal, M. (2017). Authenticity, aims and authority: navigating youth participatory action research in the classroom. Curr. Inq. 47, 175-194. doi: 10.1080/03626784.2017.1298967

Saido, G. A., Siraj, S., Nordin, A. B., and Al-Amedy, O. S. (2017). Teaching strategies for promoting higher order thinking skills: a case of secondary science teachers. Malays. Online J. Educ. Manag. 3, 16-30. Available online at: https:// ejournal.um.edu.my/index.php/MOJEM/article/download/6077/3788

Saye, J. W. (2017). "Disciplined inquiry in social studies classrooms," in The Wiley Handbook of Social Studies Research, eds M. McGlinn Manfra and C. Mason Bolick (West Sussex, UK: John Wiley \& Sons, Inc.), 336-359. doi: $10.1002 / 9781118768747 . \operatorname{ch} 15$

Senko, C., Hulleman, C. S., and Harackiewicz, J. M. (2011). Achievement goal theory at the crossroads: old controversies, current challenges, and new directions. Educ. Psychol. 46, 26-47. doi: 10.1080/00461520.2011.538646

Sickel, A. J., and Friedrichsen, P. (2015). Beliefs, practical knowledge, and context: a longitudinal study of a beginning biology teacher's 5E unit. Sch. Sci. Math. 115, 75-87. doi: $10.1111 /$ ssm.12102 
Sinatra, G. M., Broughton, S. H., and Lombardi, D. (2014). "Emotions in science education," in International Handbook of Emotions in Education, eds R. Pekrun and L. Linnenbrink-Garcia (New York, NY: Routledge), 415-436.

Splitter, L. J. (2009). Authenticity and constructivism in education. Stud. Philos. Educ. 28, 135-151. doi: 10.1007/s11217-008-9105-3

Tabachnick, B. G., Fidell, L. S., and Osterlind, S. J. (2001). Using Multivariate Statistics. Boston, MA: Allyn \& Bacon.

Thein, A. H., Guise, M., and Sloan, D. L. (2015). Examining emotional rules in the English classroom: a critical discourse analysis of one student's literary responses in two academic contexts. Res. Teach. English 49, 200-223. Available online at: https://www.researchgate.net/profile/ Amanda_Haertling_Thein/publication/279316241_Examining_Emotional_ Rules_in_the_English_Classroom_A_Critical_Discourse_Analysis_of_ One_Student's_Literary_Responses_in_Two_Academic_Contexts/links/ 5671c52608aeb8b21c6dc904/Examining-Emotional-Rules-in-the-EnglishClassroom-A-Critical-Discourse- Analysis-of-One-Students-LiteraryResponses-in-Two-Academic-Contexts.pdf

Uhrmacher, P. B., Conrad, B. M., and Moroye, C. M. (2013). Finding the balance between process and product through perceptual lesson planning. Teach. Coll. Rec. 115, 1-27. Available online at: http://citeseerx.ist.psu.edu/viewdoc/ download? doi $=10.1 \cdot 1.888 .8838 \&$ rep $=$ rep $1 \&$ type $=$ pdf

Urdan, T., and Schoenfelder, E. (2006). Classroom effects on student motivation: goal structures, social relationships, and competence beliefs. J. Sch. Psychol. 44, 331-349. doi: 10.1016/j.jsp.2006.04.003 von der Embse, N. P., and Putwain, D. W. (2015). Examining the context of instruction to facilitate student success. Sch. Psychol. Int. 36, 552-558. doi: $10.1177 / 0143034315612144$

Whitney, A. E. (2011). In search of the authentic English classroom: facing the schoolishness of school. English Educ. 44, 51-62.

Wilcox, K. C., and Jeffery, J. V. (2014). Adolescents' writing in the content areas: national study results. Res. Teach. English 49:168. Available online at: http:// scholarsarchive.library.albany.edu/etap_fac_scholar/17

Wolters, C. A. (2004). Advancing achievement goal theory: using goal structures and goal orientations to predict students motivation, cognition, and achievement. J. Educ. Psychol. 96:236. doi: 10.1037/0022-0663. 96.2 .236

Conflict of Interest Statement: The authors declare that the research was conducted in the absence of any commercial or financial relationships that could be construed as a potential conflict of interest.

Copyright (C) 2019 Jeter, Baber, Heddy, Wilson, Williams, Atkinson, Dean and Gam. This is an open-access article distributed under the terms of the Creative Commons Attribution License (CC BY). The use, distribution or reproduction in other forums is permitted, provided the original author(s) and the copyright owner(s) are credited and that the original publication in this journal is cited, in accordance with accepted academic practice. No use, distribution or reproduction is permitted which does not comply with these terms. 